\title{
Incorporating theatre techniques in the language classroom
}

\section{Abigail Paul}

This interactive workshop on performative techniques in the foreign language classroom gives teachers ideas on how to refresh their creative skill set in the classroom, while creating a supportive, collaborative environment for learners. We reinforce understanding of language as a way to communicate meaning and give teachers techniques for creating a positive classroom culture, where students feel freedom from fear of failure. The techniques outlined in this workshop widen the breadth of tools that the language teacher can use to promote students' organic use of language, helping learners of non-native languages to be experimental and create an emotional connection with text, regardless of age or language level. A collaborative environment devoid of a fear of failure helps students listen better, become more aware of each other, and focus on the present with high levels of concentration. The latter half of the workshop capitalizes on learners' heightened sense of awareness and empathy through more production-oriented games and exercises.

\section{Introduction}

The following workshop was presented at a Foreign Language and Drama Conference at the University of Reutlingen on July 10, 2015. It outlines the use of improvisational theatre techniques in the foreign language classroom by making parallels between the communicative approach to language learning and improvisational theatre techniques learned in various books read and seminars attended by the author throughout the years in numerous cities, but predominantly with Second City Chicago ${ }^{1}$, iO Chicago ${ }^{2}$, Keith Johnstone, and

\footnotetext{
${ }^{1}$ Second City Chicago is an improvisation theatre that opened in 1959, founded by Paul Sills, Viola Spolin's son, using the innovative techniques Spolin taught as its means of creating scripted material.

2 iO Chicago is an improvisational theatre in Chicago that was founded in 1981 by Del Close and Charna Halpern and is credited with long form improvisation, especially their signature piece, The Harold.
} 
Comedy Sportz ${ }^{3}$. As Friederike Klippel states, "activities are invented, but we rarely know who invented them. Like games or folk songs they are handed on from teacher to teacher" (Klippel 1985: 1). Similarly improvisational activities morph over time, with each teacher adding his or her own personal flair. The seminar is built predominantly on the games and philosophies as outlined by theatre practitioners Augusto Boal, Viola Spolin and Keith Johnstone, but from the viewpoint of the author. While these activities can be used for a variety of purposes with native and non-native English speakers in a number of areas, the focus in the following is on the second language learner.

\section{The Communicative Approach versus Improvisational Theatre Techniques}

The generally-accepted understanding of a communicative approach to language learning is that it focuses on using real-life situations to communicate information in a meaningful way, as opposed to earlier approaches that were more concerned with grammar and structure. Importantly this approach is more learner-focused than teacher-focused, with more collaboration between students in order to achieve the effect of real communication in authentic situations. The theatrical realm is ripe with opportunity for these linguistic interactions. The famous improvisational theatre practitioner Augusto Boal contends that "all human beings are actors" and that "the theatrical language is the most essential human language" (2002: 15). In his famous text Theatre of the Oppressed he systematically rejects the formal audience/performer dichotomy in favour of making all individuals aware that they can be empowered through taking up the art form themselves, either as actors or spect-actors, as he labels them (Boal 1985). This ties into the communicative approach to language learning, and is echoed in the equally famous improvisational theatre practitioner Viola Spolin's words, that "the techniques of the theatre are the techniques of communicating" (1999: 14). They are both convinced that these techniques should not be reserved only for actors with 'talent'. "Talent or lack of talent have little to do with it...what is called talented behaviour is a greater individual capacity for experiencing" (Spolin 1999: 3).

We don't merely send textual messages composed of words back and forth, but rather human communication takes place "on two levels, consciously or unconsciously" (Boal 2002: 39). Richards' (2006) explanation of the adoption of the communicative approach hints at the parallels we find in using improvisation and drama techniques as a means to learn language.

Learners now had to participate in classroom activities that were based on a cooperative rather than individualistic approach to learning. Students had to become comfortable with listening to their peers in group

\footnotetext{
${ }^{3}$ Comedy Sportz is a chain of improvisational theatres who use improvisation games in a friendly competitive format, and also offer workshops to students of all ages on how to perform improvisation games.
} 
work or pair work tasks, rather than relying on the teacher for a model. They were expected to take on a greater degree of responsibility for their own learning. And teachers now had to assume the role of facilitator and monitor. Rather than being a model for correct speech and writing and one with the primary responsibility of making students produce plenty of error-free sentences, the teacher had to develop a different view of learners' errors and of her/his own role in facilitating language learning.

(Richards 2006: 5)

The techniques of the communicative approach are not only parallel, they are in fact identical, with teachers needing to create as much opportunity as possible for students to have authentic speaking opportunities. Fundamentally, a pupil's language resources must be called upon for the sake of doing drama in the classroom in that he or she uses words in the target language and speaks. However, less important than the use of target vocabulary words, for example, is the "the need to deliberate, negotiate, implement decisions and assess consequences" (O'Neil and Lambert 1982: 18). Taking away some responsibility from the teacher and giving it to the student makes the learner more present in the experience, and thus more excited. "The teacher creates the structure for the tasks, but the learners get to fill them with their own content" (Swados 2006: 2). "Communicative exercises that emphasize learner-based approaches can significantly reduce teacher talking time" (Rinvolucri 1984: 1), which also has obvious benefits for the second language learner.

\subsection{The Collaborative/Improvisational approach}

The exercises outlined in the workshop make attempts at putting the greatest emphasis on the group learning experience and not the individual one. We build a sense of togetherness, awareness of other and mindfulness through play. We use collaboration and spontaneity to produce a safe environment where learners are more able to take risks and less likely to suffer if they 'fail'. This is an ideal situation for the language learner and the improviser. Keith Johnstone, the third improvisation icon in addition to Boal and Spolin, makes clear the importance of embracing failure. However, he states that, "the risk can't have a 100\% failure rate" (1999: 68). He gives the example of an improviser taking a suggestion from an audience member about a famous person he did not know, which ended with obvious failure. Johnstone affirms this isn't the kind of risk he means. This won't help actors on the stage, nor language learners. We have to build the level of risk according to the students' skill. For example, we would not use the games and exercises outlined in this paper to introduce new vocabulary because the risk is too high that students would not be successful or have fun. However, once a new vocabulary set or grammar structure is introduced, we can use these techniques to synthesize the learning experience, and have the new words and concepts recalled in a more authentic way.

To promote what improvisers call 'group mind,' teachers should create partnerships between students in a random order, by separating close friends, 
people of the same culture or gender, and by encouraging everyone to play with all members of the group. It is important for students to keep swapping partners and groups at every opportunity so that we may "break any dependencies to strengthen the group bond" (Spolin 1999: 30). Students should be encouraged to make "a lot of eye contact between learners to strengthen the bond between listener and speaker" (Almond 2005: 14). Once we feel that we are part of the tribe and are functioning without hierarchy, we feel a freedom to experiment and we are less likely to be judged. We are very much in the present, focused on our partners, allowing for learning in a mindful state.

In improvisation we use the term 'yes, and' to mean that we should take an idea given to us and build upon it. McKnight and Scruggs (2008: 13) make it clear how we use 'yes, and' in the classroom increases authentic communication: "The concept of 'yes, and' is a simple one. All ideas are included in activity. No idea is stupid or dumb. All ideas are accepted and built upon."

The role of humour and laughter is also an important one. "Humour cements group bonds, builds up trust and humanizes impersonal relations" (Sims et al. 1993: 163). However, we must make it clear for students that fun and laughter are the consequences of the activities outlined later, not the goal. In fact, Keith Johnstone, in workshops and repeatedly in his books, asks us to be dull, boring, mundane. He writes, "being 'obvious' means being your own person, not somebody else's" (Johnstone 1999: 71). In seminars it is vital to communicate the message to students that they are already enough, they are already interesting, as each human being brings their own experiences, culture and world-view into the lesson. Referring to personal construct theory, Sims et al. (1993: 121) contend that we "are all 'scientists' who categorize the elements of their world into constructs, and then use those constructs to help them understand what is going on." Because your systems of constructs are different from everyone else's, they are inherently personal, and infinitely interesting. It is the role of the facilitator to make the students feel comfortable in sharing their points of view, and bringing this content into the lesson. This can be done via modelling and using the teacher's own personal opinions and points of view. This may at first appear to weaken the traditional authoritarian role of the teacher, but in fact with practice the teacher becomes more aware of how to balance authority and control. Spolin criticizes authoritarian good/bad models of critiquing, arguing that the habit "develops into a way of life for those needing approval/disapproval from authority" (Spolin 1999: 8). She believes that when students start seeing their teachers and fellow students as collaborators and not judges, "fear of failure effectively dissipates" (Spolin 1999: 13). Language teaching experts Klippel (1984: 7) and Almond (2005: 50) agree that a friendly environment is of the utmost importance, where mistakes can be made without fear and that students can be uninhibited. Johnstone too shows disdain for traditional teacher student roles, and even encourages the teacher to take responsibility for students' 'failure', hoping that this behaviour will develop confidence in students, and "soon begin to resemble a good party rather than anything academic" (1999: 60). By accepting responsibility for the students' 
failures, he believes that "all students regardless of their own inhibitions will volunteer, confident that they won't be embarrassed" (1999: 60). This learning environment will begin to "generate fun for the achievement of a serious goale" (Swados 2006: 3).

\subsection{The Role of the Teacher}

In the communicative approach, it is important to first understand the function of a grammatical structure before we have a label for it, such as 'present continuous'. We also don't need to employ labels when using theatrical exercises. Avoiding labels will free analytical thought, as "it allows the player to 'share' in his or her own way, for imposing a label before its organic meaning is fully understood prevents direct experiencing" (Spolin 1999: 34). Taken from this point of view, the non-native speaker, not unlike the native speaker, first learns and then labels what is then known at a later date, or perhaps not at all.

Spolin (1999) and Johnstone (1999) both encourage an organic approach to exercises, and the teacher's personal ability to be spontaneous, changing quickly to meet the needs that arise. In this respect, it is more useful for the teacher to have an understanding of the underlying philosophy of improvisation and to have a relatively large number of games in the repertoire, so that the teacher can act as diagnostician. As exercises, grammar structures, and even behavioural issues arise in the classroom, the appropriate game or exercises can be applied as needed. It is also important to respect the boundaries of each individual student in this type of learning environment: "The challenge to the teacher or leader is to activize each student in the group while respecting each one's immediate capacity for participation" (Spolin 1999: 10). If, for example a group of students find it difficult to play I am a Tree because of a lack of vocabulary choices, the teacher might quickly switch gears to a different improvisation game such as Categories ${ }^{4}$ to prime the students better for success. Teachers can use these exercises as one set of activities together, or individually to help solve a specific classroom challenge. It is important that the teacher can also feel the freedom to fail so that she can refine, hone, and vary activities in her own style for the best outcomes.

\section{The Workshop Activities}

The following activities can be used on an individual basis, but as they are presented here, it is one workshop, using scaffolding techniques to get learners to bridge one skill to the next. ${ }^{5}$

\footnotetext{
${ }^{4}$ Categories is an improvisation game not listed in the workshop activities. Three players come up and form a line in front of the rest of the group. They are given a category (e.g. languages, vegetables, school subjects). Players take turns naming as many things from that category as they can. If there is too long a pause, a mistake or a repetition of something that has already been mentioned, he/she is out and replaced with another player. It can be used to reinforce vocabulary sets students have learned.

${ }^{5}$ See also improvencyclopedia.org.
} 


\subsection{Names to the left/right}

The group stands in a circle. In this warm-up exercise, the teacher looks to the person on their left and says their own name to that person. Go around the whole circle once, with students looking at and saying their names to the person to their left. Once it comes back to the teacher, send the names to the right. Then create a rule where the direction of the pulse can change, depending which way the player who has the pulse looks. The focus here is on creating a flow of energy and connecting with other students.

\subsection{Name Snap Concentration}

The group stands in a circle. Create a rhythm together, two beats softly on the hips, and then a right snap, left snap, for four beats total. Then throw names around circle in random order, Cindy, Jeff, (now Jeff has control). Jeff, Aron, (now Aron has control) etc. The focus here is on solidifying the names learnt in the previous exercise and creating a rhythm as a group.

\subsection{Speak or Point}

The group stands in a circle. Players take turns either saying the name of a nearby player OR speaking the name. Point/speak/point/speak; it must stay in the order of either speaking, then pointing. Once the pattern is established, play more quickly. The focus here is creating rhythm and recognising patterns. We can also make plenty of mistakes in this game, as it is challenging, but the consequences are usually only laughter.

\subsection{You, yes}

The group stands in a circle. One person makes eye contact with another and points at them. The pointee says, 'yes' to acknowledge the offer. Once they hear 'yes', the pointer walks across the circle to take the pointee's place. In the meantime the pointee has become the pointer, and must look to someone else to get a place in the circle. It is important that the players don't move from their spot until they have permission to get someone else's.

- Variation - substitute the players' name with 'you', to make it a name game. This exercise is important for making students say yes to everything, but also helps practice authentic listening and give and take.

\subsection{Alphabet letters (in pairs)}

Students will need space to carry out this exercise. In groups of two, players will become letters of the alphabet. When a letter is called, they become the 
letter together without speaking about their plan, simply becoming the letter 'A.' It can be upper case or lower case, but the key is agreement.

- Variation a - create different sized-groups, such as three, four, five or more students. The focus here is on how the exercise changes when more players are added.

- Variation b-Call the numbers at random, instead of alphabetically. The focus here is on spontaneity and allowance for more risk-taking.

\subsection{0 -second objects (in two large groups)}

Students will need space to carry out this exercise. The teacher divides the students into two groups. (This can work with very large groups, so the number of students in each group is unimportant, just that there is one group which actively does the activity and one which serves as an audience.) The teacher calls out an object, then counts to ten as the group becomes the object (e.g. a car, sofa, a pair of glasses).

- Variation for advanced learners - let one student from the opposite group explain the frozen object. The teacher might offer a helpful prompt such as, 'These are no ordinary glasses, Jimmy tell us about the glasses we are looking at!' Allowing some of the advanced students to do the descriptions is a good way of differentiating the task for stronger learners. The focus here is on spontaneity and agreement. It also aims to reinforce vocabulary sets. For the advanced variation, learners can practice spontaneous speech, and justifying what they see in the shapes.

\subsection{I am a Tree}

Students will need space to carry out this exercise. The group stands in a circle. Someone steps into the space and becomes something and says what they are. Example: "I'm a tree." Someone else enters the space and becomes something that will complement the tree: "I'm a squirrel." And a third enters embodying something that will complement both the squirrel and the tree: "I'm a nut." The oldest player chooses one of those things to 'keep': "I'll keep the nut." The students who were the squirrel and tree return to the circle. The 'kept' person who was the nut repeats what he/she is: "I'm a nut." A new tableau is made around the nut. Example: "I'm a nut." "I'm a seed." "I'm a vegetarian."

The focus here is on word association, collaboration, vocabulary building and the seedlings of storytelling. As objects leave the picture, one key element remains, but will transform into a new idea. For example in the previous example, a scene from nature transforms into a human being who prefers vegetarian food. In the next iteration, we might see a vegetarian, a pizza chef and a coffee barista. There are no wrong answers on the associations students can make. 


\subsection{Thank You Statues}

The group stands in a circle. One person steps in and creates a tableau. Then a second person comes in and complements the 'statue'. One person from the circle gives it a title. The oldest person in the statue says, 'Thank you, plus the title they were given' and exits. A new person enters and a new statue is created.

The focus here is on continuing to practice idea transformation, but also on listening to each other's ideas and labelling them. When we thank our fellow student, we acknowledge that they have been heard. Creating titles for the statues is a creative way for students to use their vocabulary, but also to look for meaning in a stage picture that has been created. As any label is correct, the students learn that all their answers are good, further emphasizing a no-failure feeling in the classroom.

\subsection{Mirroring}

Students need a partner. Label each person A or B. A will be B's mirror. A must follow B exactly as if he were looking at himself in the mirror. Once students have understood this part of the exercise, B leads A, when the teacher yells 'switch' to change leadership. The teacher continues to call A or B at random, indicating that the leadership should change. Then students are directed to switch leadership organically, until no one leads, we are following the follower.

- Variation - Voice mirroring. Do this same activity using sounds (at first) and then moving on to words. The purpose of mirroring exercises is to make us actively listen with our bodies and voices. When students are listening for context in conversation, they are less reliant on understanding every single vocabulary word.

\subsection{Communal Love/Communal Moan}

Pick a topic we all love or we want to moan about. One person in the middle of the circle of students begins speaking freely. When s/he runs out of steam, a player from outside the circle continues the conversation by tagging in with a tap on the shoulder and picking up the thread. Everything players say should be true, no need to make anything up. What is very important is that the people on the outside of the circle understand that they must go in to help the 'it' person in the middle, not wait to go in until they have a great idea.

- Variation for reluctant learners, the coach/teacher gives a gentle tap on the back to force reluctant people to go in the circle, to balance more dominant speakers. The focus here is on free speaking, expressing opinions and listening to our fellow students. 


\subsection{Story Exchange}

In groups of two, one student creates a (completely fictional) story about their partner in second person ("you walked into the forest one day, then you saw a squirrel, which you are very afraid of..."). The listener must retell their story in first person ("I was walking in the forest one day when I saw a squirrel", etc.). Make sure both partners have a turn to create and retell their stories. The focus here is on active listening and storytelling.

\subsection{Panel of Experts}

Three to four students are told they are experts on one subject (usually a noun + gerund combo - banana throwing, kitten tossing, etc.). The teacher leads the panel discussion on the subject with the experts, and fellow students may ask questions about the topic.

The focus here is on listening, collaboration, and confidence in speaking. By transforming learners into 'experts' we see a total change in their posture and voices, and with the no-failure rule, they can't be wrong. This game is also very good in helping students to support each other's ideas, by saying yes to the reality that the experts create together. Students should be encouraged to expand on any details created by their fellow students, and create as much reality as possible about their given topic.

\section{Conclusion}

Combining improvisational techniques with a communicative approach to language learning can open up students and increase their confidence by creating an opportunity for authentic dialogue. A fun, collaborative environment that is devoid of fear of failure results in stronger linguistic outcomes. These techniques aim to "develop people, not drama. By pursuing the former, the latter may also be achieved" (Way 1967: 7).

\section{Bibliography}

Almond, Mark (2005): Teaching English with Drama. How to use drama and plays when teaching - for the professional language teacher. Hove: Keyways Publishing

Boal, Augusto (2002): Games for Actors and Non-Actors. Second Edition. London: Routledge

Boal, Augusto (1985): Theatre of the Oppressed. New York: Theatre Communication Group

Johnstone, Keith (1999): Impro for Storytellers. London: Routledge

Klippel, Friederike (1985): Keep Talking: Communicative Fluency Activities for Language Teaching. Cambridge: Cambridge University Press 
McKnight, Katherine \& Scruggs, Mary (2008): The Second City Guide to Improv in the Classroom: Using Improvisation to Teach Skills and Boost Learning. San Francisco: Jossey-Bass

O'Neil, Cecily \& Lambert, Alan (1982): Drama Structures. A practical handbook for teachers. London: Hutchinson

Richards, Jack (2006): Communicative Language Teaching Today. Cambridge: Cambridge University Press

Rinvolucri, Mario (1984): Grammar Games. Cognitive, affective and drama activities for EFL students. Cambridge: Cambridge University Press

Sims, David, Fineman, Steven, Yiannis, Gabriel (1993): Organizing and Organizations : an introduction. London: Sage Publications

Spolin, Viola (1999): Improvisation for the Theatre. Third Edition. Noyes St. Evanston: Northwestern University Press

Swados, Elizabeth (2006): At Play: Teaching Teenagers Theater. London: Faber and Faber

Way, Brian (1967): Development through Drama. London: Longman 